\title{
Role of diffusion-weighted imaging and dynamic contrast enhanced magnetic resonance imaging in the diagnosis of early sacroiliitis in seronegative spondyloarthropathies, correlation with levels of acute phase reactants
}

\author{
Sibel AYDIN AKSU' ${ }^{1}$ (D), Hasan GUNDOGDU² (D) \\ ${ }^{1}$ Department of Radiology, Haydarpaşa Numune Training and Research Hospital, University of Health Sciences, Istanbul, Turkey. \\ ${ }^{2}$ Department of Radiology, School of Medicine, Recep Tayyip Erdogan University, Rize, Turkey.
}

Corresponding Author: Sibel AYDIN AKSU

E-mail: drsibelaydin@yahoo.com

\begin{abstract}
Objective: Seronegative spondyloarthropathy $(\mathrm{SpA})$ is a destructive disease. Early diagnosis is crucial to prevent morbidity. Magnetic resonance imaging (MRI) is the only imaging modality that can show early sacroiliitis. We aimed to investigate the utility of dynamic contrast enhanced magnetic resonance imaging (DCE-MRI) and diffusion-weighted imaging (DWI) in the detection, quantification and staging of early/acute SpA. We also investigated the relationship between contrast enhancement properties and apparent diffusion coefficient (ADC) values with laboratory parameters for inflammation such as ESR and CRP measurments.

Patients and Methods: Dynamic contrast-enhanced magnetic resonance imaging and DWI were performed on 85 patients that fulfilled the criteria. A positive MRI finding was defined as inflammation in subchondral bone representing active sacroiliitis. Kinetic analyses were performed, apparent diffusion coefficient (ADC) values were calculated, ESR and CRP levels were measured for quantification of inflammation. Statistical analyses were performed.

Results: In acute SpA group; quantity, area and level of enhancement, values of ADC and Fenh, levels of CRP were significantly higher than those with chronic SpA. A high level of agreement was found between the ADC threshold value of $0.831 \times 10^{-3} \mathrm{~mm} 2 / \mathrm{s}$ and diagnosis according to Assessment of SpondyloArthritis International Society (ASAS) criteria (Kappa=0.794;p<0.001).

Conclusion: Dynamic contrast-enhanced magnetic resonance imaging and DWI are advanced MR techniques which enable quantification of active inflammation. They are hallmarks for early SpA. Their combined use is superior to one alone in the diagnosis of early sacroiliitis.

Keywords: Seronegative spondyloarthropathy, Early sacroiliitis, Dynamic contrast enhanced magnetic resonance imaging, Diffusionweighted magnetic resonance imaging, Acute phase reactants
\end{abstract}

\section{INTRODUCTION}

Seronegative spondyloarthropathy $(\mathrm{SpA})$ is a heterogeneous group of rheumatic disease with unknown aetiology [1]. The spectrum comprises three clinical components as axial SpA, peripheral SpA, and extra-articular manifestations [2]. The diagnosis of axial SpA is mainly based on clinical manifestations related to imaging findings and laboratory data [3].

Seronegative spondyloarthropathy is a disabling disease that directly affects the quality of life, so early diagnosis is a crucial step due to new treatment options that can be available, to regress the inflammation and delay disease progression $[4,5]$.
The Assessment of SpondyloArthritis International Society (ASAS) criteria for classification of axial spondyloarthritis introduced active sacroiliitis as one of the most important factors in the classification of SpA [3]. Magnetic resonace imaging (MRI) of the sacroiliac joints (SIJs) plays a key role in early diagnosis because active inflammatory lesions of sacroiliitis can be visible long before structural changes are detectable on radiograpy or computed tomography (CT). Thus, in 2009, ASAS published new criteria for SpA and added an magnetic resonance imaging (MRI) definition to enable the identification of patients without evidence of structural change

How to cite this article: Aksu Aydin S, Gundogdu H. Role of diffusion-weighted imaging and dynamic contrast enhanced magnetic resonance imaging in the diagnosis of early sacroiliitis in seronegative spondyloarthropathies, correlation with levels of acute phase reactants. Marmara Med J 2022: 35(1):79-87. doi: 10.5472/marumj.1061146 
on radiography. The major MRI finding of active sacroiliitis is osteitis $(\mathrm{O})$ or bone marrow oedema (BMO) owing to its importance in the early diagnosis of SpA. Other signs of inflammation, such as enthesitis, capsulitis, and synovitis, can also be observed on MRI [3,6].

Dynamic contrast enhanced magnetic resonance imaging, allows quantification of inflammation by measuring the distribution profile of paramagnetic contrast medium in microvessels and interstitial spaces of the tissues investigated [7]. Synovitis/capsulitis as an indicator of active inflammation can only be shown after contrast administration, so DCEMRI provides significant additive information to evaluate inflammation.

Diffusion-weighted imaging is an MR based technique that produces image contrast by the different randomized motions of water protons in various biological tissues. Numerous studies have been reported that DWI is a useful tool for detecting inflammatory lesions and quantitative monitoring of inflammatory activity in patients with $\mathrm{SpA}[8,9]$.

Management of SpA is based on assessment of disease activity determined by clinical signs and symptoms and levels of acute phase reactants such as C-reactive protein (CRP) and erythrocyte sedimentation rate (ESR) in addition to structural changes. These are established measures of disease activity to increase sensitivity for diagnosing and monitoring the disease $[10,11]$.

The purpose of this study was to determine the role of DCE-MRI and DWI in the diagnosis of acute (early) sacroiliitis in patients with axial SpA. We also investigated the relationship between contrast enhancement properties and apparent diffusion coefficient (ADC) values with laboratory parameters for inflammation such as ESR and CRP measurements.

\section{PATIENTS and METHODS}

This study was conducted according to Good Clinical Practice guidelines and was approved by the Haydarpasa Numune Training and Research Hospital Ethics Committee (17.03.2014, 2014/18). Informed consent was obtained from all patients prior to examination.

\section{Patient Selection}

The study population comprised 98 patients who were referred by the clinicians from the departments of Physical Medicine and Rehabilitation, Internal Medicine and Gastroenterology, between March 2014 and September 2017. The patients were evaluated with the guidance of ASAS. All of them underwent
DCE-MRI. 85 patients that fulfilled the diagnostic criteria for SpA were enrolled in the study.

Thirteen patients were excluded because of not meeting the ASAS criteria, received other diagnoses such as osteoarthritis, with a history of injury or malignancy, and insufficient quality of the images.

\section{MRI acquisition}

All the patients were examined on a $1.5 \mathrm{~T}$ MRI scanner (GE Optima MR450w) using a 6-channel body coil, in the supine position and the knees flexed $15^{\circ}$. The acquisition was planned in paraaxial images which were parallel to the long axis of the upper part of the sacrum (at an angle of approximately 30$45^{\circ}$ to the body axis) and coronal oblique images which were perpendicular to the paraaxial plane, after the sagittal scout image was taken.

Imaging protocol was performed as follows; Coronal Oblique and Axial T1W sequences (TR/TE: 680/42 ms, matrix: $256 \times$ 256, NEX: 2, Slice Thickness: $3 \mathrm{~mm}$, flip angle 90 and FOV: 20 $25 \mathrm{~cm}$ ), Coronal Oblique T2* GRE sequence (TR/TE: 613/7 ms, matrix: $256 \times 256$, NEX: 2, Slice Thickness: $3 \mathrm{~mm}$, flip angle 90, FOV: $20-25 \mathrm{~cm}$ ), Coronal Oblique Short Tau Inversion Recovery (STIR) sequence (TR/TE: 4000/85 ms, matrix: $256 \times 256$, NEX: 2, Slice Thickness: $3 \mathrm{~mm}$, flip angle 90, FOV: $20-25 \mathrm{~cm}$ ), Coronal Oblique DWI sequence(single-shot spin-echo echo-planar imaging (EPI), b=400/b=800 mm2/s, TR/TE:5200/70 ms, matrix $192 \times 192$, NEX: 2, Slice Thickness: 3 mm, flip angle 90, FOV: 20-25 cm), Coronal precontrast and postcontrast dynamic fat sat T1W sequence; (TR/TE:400/20 ms, matrix: $256 \times 256$, NEX: 2, Slice Thickness: $3 \mathrm{~mm}$; flip angle 10 and FOV: $20-25 \mathrm{~cm}$ ). Dynamic imaging was performed after injecting Gadoterate Meglumine (Dotarem ${ }^{\oplus}$, Guerbet, France) in the antecubital vein at $0.1 \mathrm{mmol} / \mathrm{kg}$, the flow rate at $3 \mathrm{ml} / \mathrm{sec}$. Consecutive $1^{\text {st }}, 2^{\text {nd }}, 3^{\text {rd }}$ and $4^{\text {th }}$ minute images were obtained (Figures 1a-f and Figures $2 a-g$ ).

The DWI original data were analyzed using GE workstation 3.0. ADC maps were obtained. $80-100 \mathrm{~mm}^{2}$ circular ROI's were placed on the hypointens lesions, an average value of ADC was calculated. The ROI selection was performed by avoiding the joint space, bone cortex, bone sclerosis area, blood vessels, and artifacts. 
1a

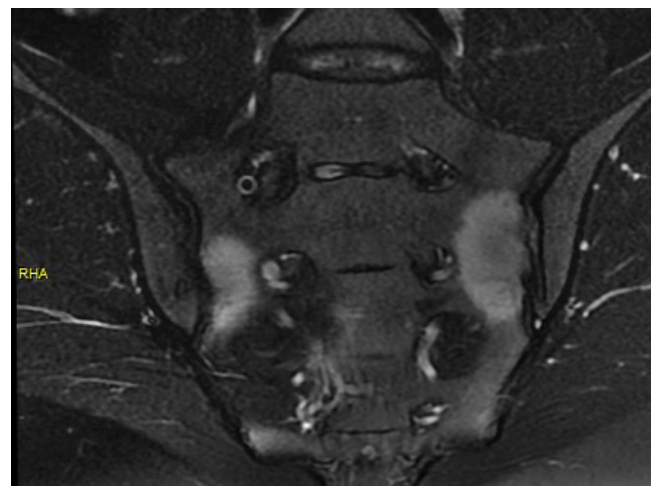

$1 \mathrm{c}$

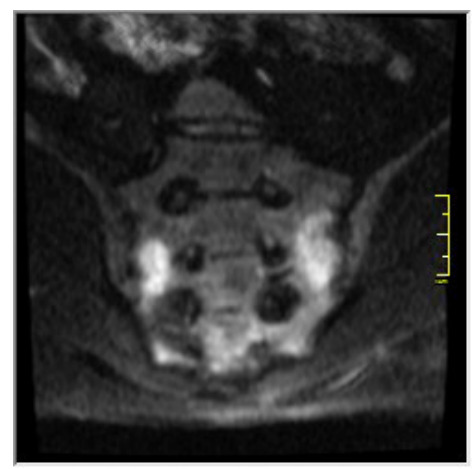

$1 \mathrm{~b}$

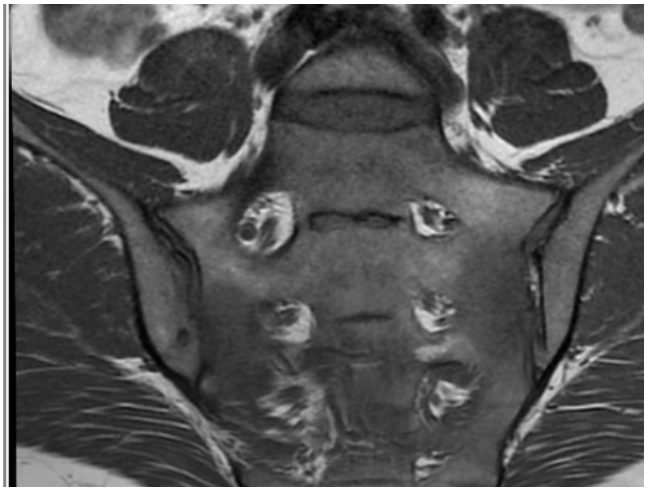

1d

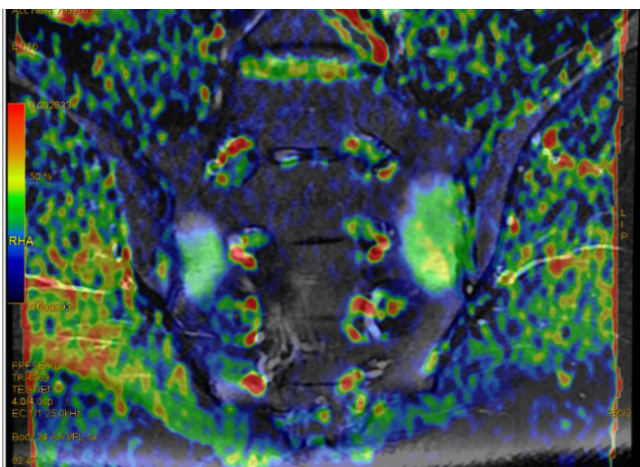

1e
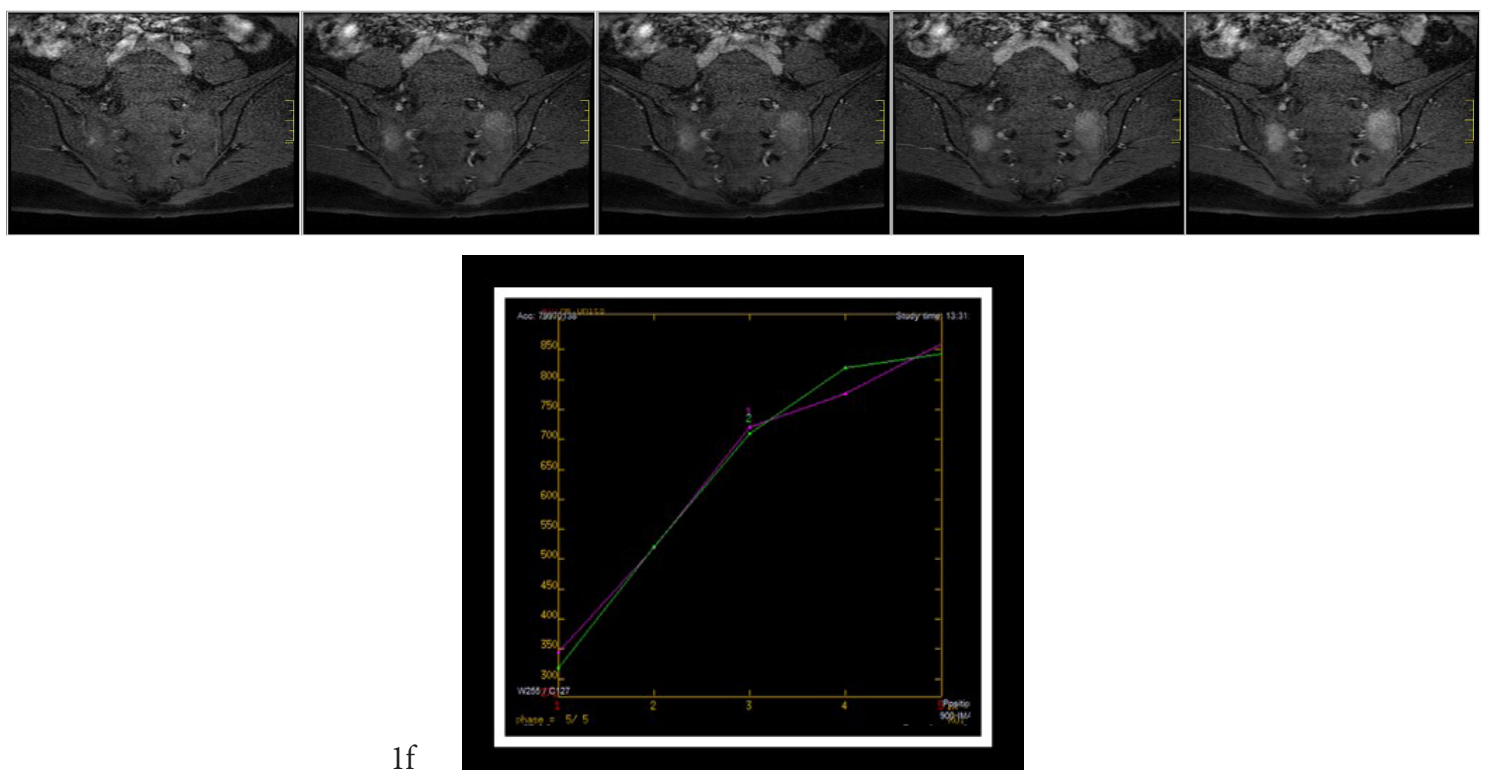

Figure 1(a-f). MRI of SIJ's in semicoronal planes in a 26-year-old male with inflammatory low back pain of 4 months duration. CRP was 42.3 mg/L . (a) STIR sequence shows abnormal increased signal in sacrum bilaterally, typical for BMO/O due to acute inflammatory sacroilitis. Lesions are periarticularsubchondral in location, of significant size. (b) There are corresponding areas of diminished signal intensity on the T1W sequence. (c,d) Affected regions show restricted diffusion with high signal intensity on DWI. (e) On dynamic contrast enhanced series, lesions show progressive enhancement rising with time. (f) On the kinetic analysis, a Type 3 TSI curve is obtained with a rapid initial upslope followed by a persistent rise 
$2 \mathrm{a}$

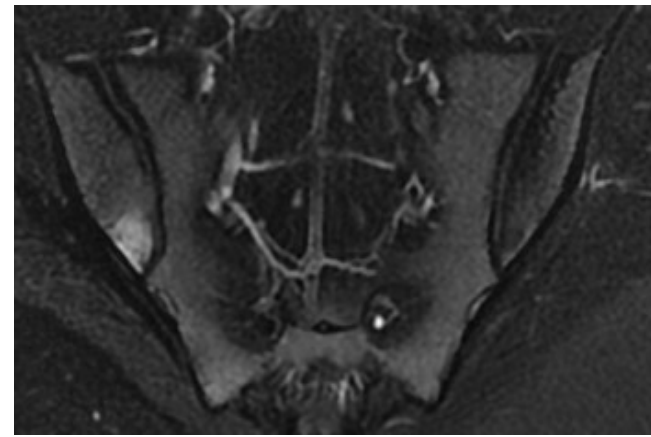

$2 c$

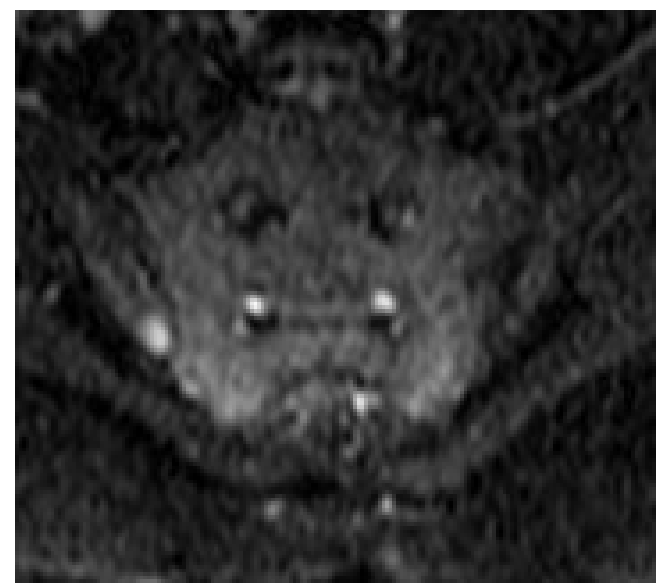

$2 \mathrm{~b}$

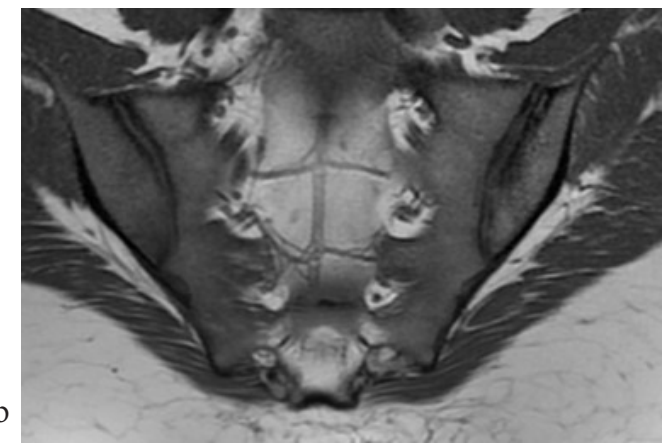

$2 d$

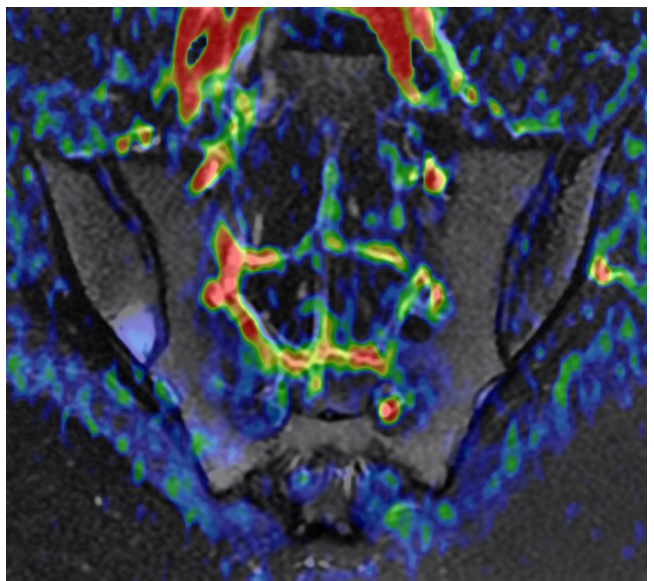

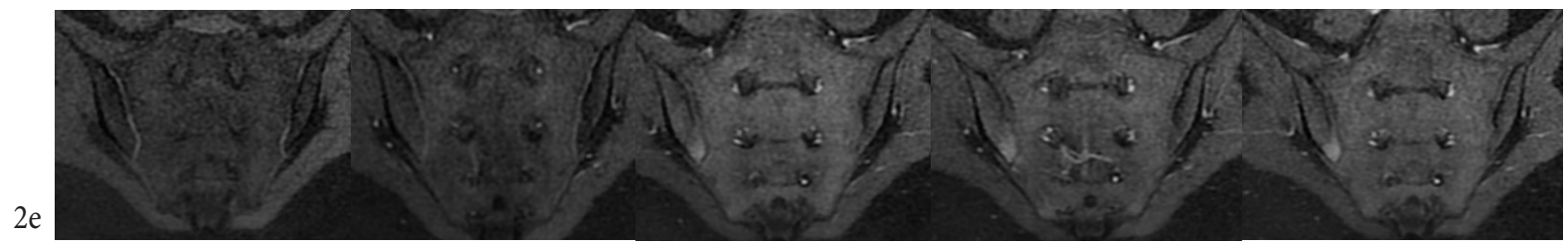
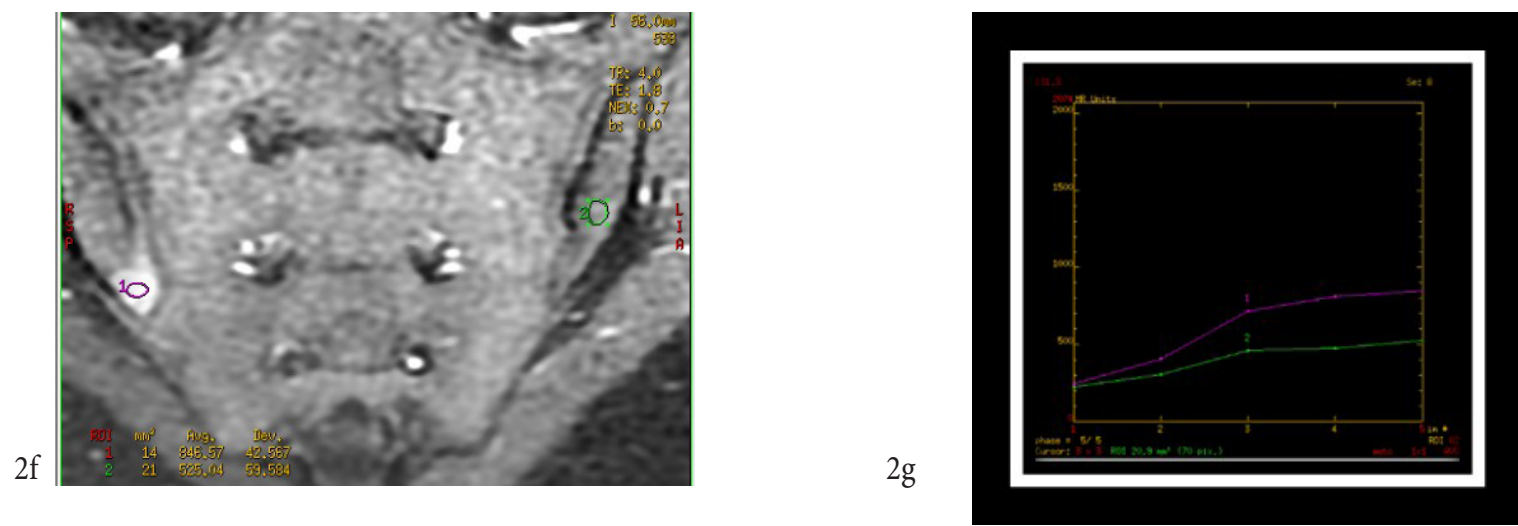

Figure 2(a-g). A 32-year-old male with inflammatory low back pain of more than 1 year duration. CRP was $21.2 \mathrm{mg} / \mathrm{L}$. (a) STIR sequence shows a subchondral high signal area at the iliac side of the right SIJ pointing to acute inflammation. (b) There is a corresponding focus of low signal intensity on the T1W sequence. Additionally, bilateral periarticular subchondral sclerosis is present on iliac and sacral aspects of SIJ's as hypointensities on STIR and $T 1 W$ sequences consistent with chronic. (c,d) The lesion shows restricted diffusion on DWI. (e) On dynamic contrast enhanced series, the lesion shows delayed enhancement rising with time compared with the contralateral iliac bone. $(f, g)$ On the kinetic analysis, a Type 2 TSI curve is obtained with a slow initial upslope followed by a continued slow rise 


\section{Image analysis}

Images were analysed by a radiologist with 5 years of experience in musculoskeletal imaging, blinded to clinical and laboratory data, at GE workstation 3.0.

Active lesions in sacroiliitis were defined as;

1. Bone Marrow Oedema; subchondral increased signal intensity in the bone marrow on short tau inversion recovery (STIR) or fat-saturated T2W (FS-T2W) sequence, in typical anatomical areas for SpA inflammation (Figure 1a and Figure 2a), 2. Enthesitis; increased signal in the bone marrow and/ or soft tissue on STIR and/or fat-saturated T1W (FS-T1W) postcontrast images at sites where ligaments and tendons attach to the bone, 3. Capsulitis; increased signal on STIR and/or FST1W postgadolinium images at sites where synovia is present, 4. Synovitis; Gadolinium-enhanced synovium and increased synovial volume detected by MRI.

Structural lesions in sacroiliitis were defined as;

1. Erosion; a defect in the subchondral bone with loss of the dark signal of the subchondral bone plate, 2. Fat Metaplasia; subchondral increased signal intensity reprehensive of fat in the bone marrow on T1 and decreased signal on STIR or FS-T2W sequences, 3. Backfill; the presence of high T1 signal intensity within an erosion at the joint surface, 4 . Ankylosis; bony bridges or confluent high $\mathrm{T} 1$ signal intensity bridging across the joint space to connect between the ilium and sacrum, 5. Sclerosis; area with very low signal intensity on all sequences located in the subchondral bone with a depth of at least $5 \mathrm{~mm}$.

According to ASAS, a 'positive MRI' was defined as the observation of inflammation in the subchondral bone representing active sacroiliitis. Without the presence of $\mathrm{BMO} / \mathrm{O}$; neither other findings of active inflammation nor structural lesions reflecting old inflammation are sufficient for diagnosis [3].

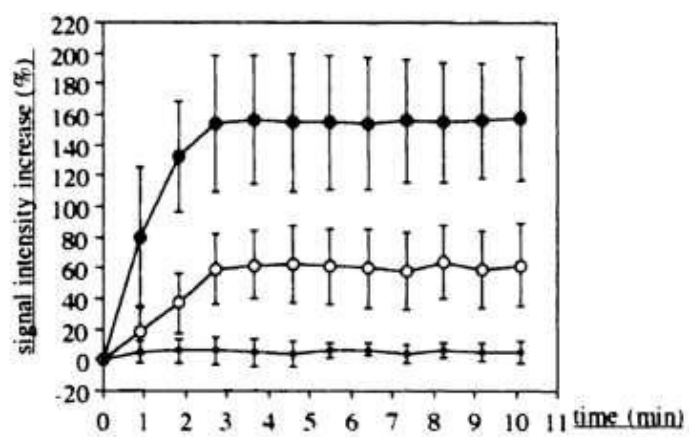

Figure 3. Time-signal intensity (TSI) curves. The kinetic analysis revealed three types of curves that showed either a plateau (Type 1 curve), or an increase with slow initial upslope (Type 2 curve) or rapid initial upslope (Type 3 curve).

On DCE-MRI, in the presence of contrast enhancement, a timesignal intensity (TSI) curve was obtained by placing an 80-100 $\mathrm{mm}^{2}$ circular region of interest (ROI) in maximum enhanced area of the articular cartilage, synovium, joint capsule, and subchondral bone marrow (Figure 2f). The kinetic analysis took four minutes of repetitive scanning in total and led to three types of the curve which showed either a plateau, or an increase with slow initial upslope or rapid initial upslope (Figure 3). The initial signal intensity $\left(\mathrm{SI}_{0}\right)$ and the maximum signal intensity $\left(\mathrm{SI}_{\max }\right)$ were automatically exhibited on the curve. Additionally, the semiquantitative index enhancement factor $\left(\mathrm{F}_{\mathrm{enh}}\right)$ was calculated from the time-signal intensity curve by using OriginPro software (Origin Lab, Northampton, MA, USA). The following mathematical formula was used for the measured data and expressed as \%.

$$
\mathrm{F}_{\mathrm{enh}}=\frac{\mathrm{SImax}-\mathrm{SIO}}{\mathrm{SIO}} \times 100
$$

Depending on data derived from DCE-MRI cases were classified as:

1. $\mathrm{F}_{\text {enh }}<20 \%$ and TSI curve upslope $<10 \%$ (Type 1 curve); no sacroiliac inflammation,

2. $\mathrm{F}_{\text {enh }}>20 \%$ and TSI curve upslope $>10 \%$ (Type 2 curve); mild sacroiliac inflammation,

3. $\mathrm{F}_{\text {enh }}>90 \%$ and TSI curve upslope $>40 \%$ (Type 3 curve); severe sacroiliac inflammation.

In the presence of active sacroiliitis, the activity index was categorized as > follows: $\mathrm{F}_{\text {enh }} \leq 25 \%$ (Grade X), $\mathrm{F}_{\text {enh }} 25 \%-70 \%$ (Grade A), $\mathrm{F}_{\text {enh }} 70 \%$ (Grade B).

On DWI, selected ROI's were placed on the obvious lesions in the image whose location and the area were consistent with the previous images. Average value of ADC was calculated and

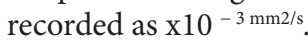

As acute-phase reactants, CRP and ESR are established measures of disease activity. Blood tests were performed 2 to 5 days before $\mathrm{MR}$ imaging. $\mathrm{ESR} \geq 20 \mathrm{~mm} / \mathrm{hr}$ and/or $\mathrm{CRP} \geq 0.5 \mathrm{mg} / \mathrm{L}$ values were considered high.

\section{Statistical Analysis}

IBM SPSS Statistics, Version 23.0 (SPSS Inc., Chicago, USA) and MedCalc ${ }^{\circledast}$ Statistical Software Version 20 (MedCalc Software Ltd, Ostend, Belgium; https://www.medcalc.org; 2021) analysis programmes were used in this study. Descriptive statistics for both groups were reported as frequency and percentages within the groups (n, \%). Before analyzing the relationship of continuous numerical variables between groups, normality testes were performed considering the number of samples in the groups, such as Kolmogorov-Smirnov and Shapiro-Wilk tests, and histogram graphics. Accordingly, normally distributed variables were reported as mean \pm standard deviation, and nonnormally distributed variables were reported as median (minmax). Student's t-test, in which the mean values were compared for those with normal distribution, and the Mann-Whitney U test, where the median values were compared for those who did not show normal distribution, were used to analyze the difference between the two groups in terms of numerical variables. The 
difference in the distribution of categorical data between the groups was evaluated with the Chi-square test. Relationships between parameters were evaluated with Pearson or Spearman correlation tests and Kappa concordance analyses. ROC curve analyses were implemented to evaluate the performance of the parameters in the diagnosis of acute sacroiliitis and to determine the appropriate threshold values. Accordingly, AUC, sensitivity and specificity values were reported. $P$ values less than 0.05 were considered significant.

\section{RESULTS}

Among 85 patients who were diagnosed as SpA based on clinical and imaging findings, $36 \%(n=31)$ were identified as acute $S p A$, while $64 \%(n=54)$ were in the chronic SpA group.

In acute SpA group; 13 (41.9\%) of 31were female and 18 (58.1\%) were male. The median age was $32(18-45)$ years. There was no statistical difference in terms of gender between acute and chronic SpA patients $(\mathrm{p}=0.123)$. However, patients with chronic SpA were significantly older $(\mathrm{p}=0.033)$.

Involvement of the SIJs, was unilateral in 11 out of $31(35.5 \%)$ acute cases, and bilateral in 20 (64.5\%). Of those with unilateral involvement, 5 (45.5\%) had right joint inflammation, and 6 (54.5\%) had left joint inflammation.

The median CRP level in patients with active sacroiliitis was 0.56 $\mathrm{mg} / \mathrm{dL}(0.01 \mathrm{mg} / \mathrm{dL}-4.49 \mathrm{mg} / \mathrm{dL})$ and the median ESR level was $19 \mathrm{~mm} / \mathrm{hr}(1 \mathrm{~mm} / \mathrm{hr}-78 \mathrm{~mm} / \mathrm{hr})$. CRP values of patients with acute SpA were significantly higher than those with chronic SpA $(\mathrm{p}=0.037)$. There was no statistical difference between the two groups in ESR values $(\mathrm{p}=0.154)$.

The mean and the median ADC measurements of the acute SpA cases were $1.05 \pm 0.57 \times 10^{-3} \mathrm{~mm} / \mathrm{s}$ and $0.84\left(0.4-2.61 \times 10^{-3}\right.$ $\mathrm{mm} 2 / \mathrm{s})$, respectively. They were significantly higher than the patients with chronic SpA $(\mathrm{p}<0.001$ and $\mathrm{p}=0.027)$. Demographic characteristics, laboratory findings and mean ADC values of the patients are summarized in Table I.

On DCE-MRI, SIJs were contrast enhanced in 27 (87.1\%) cases with acute SpA, but there was only1 case (1.8\%) among patients with chronic SpA. Enhancement was significantly higher in patients with acute SpA than those with chronic SpA $(\mathrm{p}<0.001)$. The rate of being acute was considerably higher in cases with contrast enhancement than those without contrast enhancement $(\mathrm{p}<0.001)$. TSI curves in the acute group were as follows with decreasing frequency; Type 2 curve in 15 cases (48.3\% ), Type 3 curve in 13 (41.9\%), and Type 1 curve in 13 (41.9\%). Type 2 and Type 3 curves were not obtained in any of the chronic SpA patients. The activity index was detected as grade $\mathrm{B}$ with the highest frequency (64.5\%). Furthermore, in the group showing contrast enhancement, $\mathrm{ADC}$ values were significantly higher than those who lacked enhancement $(\mathrm{p}<0.001)$, likewise CRP and ESR measurements $(\mathrm{p}=0.032$ and $\mathrm{p}=0.037$, respectively).
Table I. Demographic, laboratory, and imaging characteristics of the acute SpA and chronic SpA groups

\begin{tabular}{|c|c|c|c|c|}
\hline \multicolumn{2}{|l|}{ Characteristics } & Acute SpA & Chronic SpA & $\underset{\text { value }}{\mathrm{p}}$ \\
\hline \multirow{2}{*}{ Gender, $\mathbf{n}(\%)$} & Male & $18(58.1)$ & $22(40.7)$ & \multirow{2}{*}{0.123} \\
\hline & Female & $13(41.9)$ & $32(59.3)$ & \\
\hline \multicolumn{2}{|c|}{ Age (years), median (min-max) } & $32(18-45)$ & $36(21-61)$ & 0.033 \\
\hline \multirow{2}{*}{$\begin{array}{l}\text { Contrast } \\
\text { enhancement, } \\
\mathbf{n}(\%)\end{array}$} & $(-)$ & $4(12.9)$ & $53(98.1)$ & \multirow[b]{2}{*}{$<0.001$} \\
\hline & $(+)$ & $27(87.1)$ & $1(1.9)$ & \\
\hline \multicolumn{2}{|c|}{ CRP (mg/L), median (min-max) } & $0.56(0.01-4.49)$ & $0.2(0.01-4.7)$ & 0.037 \\
\hline \multicolumn{2}{|c|}{$\operatorname{ESR}(\mathrm{mm} / \mathrm{hr}), \mathrm{n}(\%)$} & $19(1-78)$ & $14(3-68)$ & 0.154 \\
\hline \multirow{2}{*}{$\underset{\mathrm{m} m 2 / \mathrm{s}}{\operatorname{ADC}}\left(\mathrm{x}^{\mathrm{N} 10^{-3}}\right.$} & mean \pm SD & $1.05 \pm 0.57$ & $0.57 \pm 0.12$ & $<0.001$ \\
\hline & $\begin{array}{l}\text { median (min- } \\
\max )\end{array}$ & $0.84(0.4-2.61)$ & $\begin{array}{c}0.612(0.3- \\
2.07)\end{array}$ & 0.027 \\
\hline
\end{tabular}

The diagnostic performance of ADC values for acute SpA was evaluated using ROC curve analysis. It was revealed a sensitivity of $83.9 \%$ and a specificity of $94.4 \%$ for cut-off value of $>0.831 \times 10$ $-3 \mathrm{~mm} 2 / \mathrm{s}$ (AUC: 0.903 ; p<0.001) (Figure 4). Furthermore, a high level of agreement was found between this ADC threshold value and diagnosis according to ASAS criteria (Kappa=0.794; $\mathrm{p}<0.001)$.

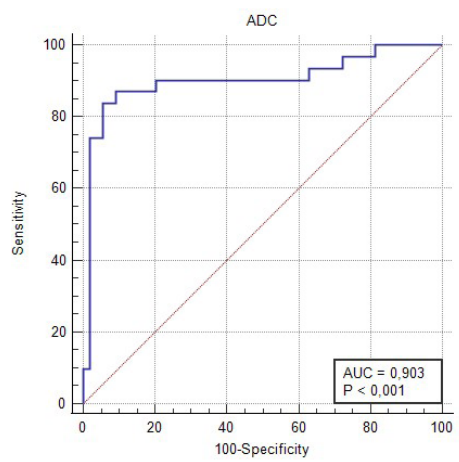

Figure 4. ROC curve analysis for the diagnostic performance of $A D C$ values

Consequently, 28 among 31 (90.3\%) cases with acute SpA were diagnosed on MRI. While 27 ( $87.1 \%)$ of them were detected by DCE-MRI, 26 (83.9\%) cases were diagnosed by DWI features.

\section{DISCUSSION}

Early diagnosis of sacroiliitis allows reducing morbidity by suggesting an effective treatment plan and appropriate follow-up protocol in patients with SpA [12].

Clinical evaluation has a limited place in the acute SpA diagnosis. Definitive diagnosis is usually achieved via radiological evaluations [13]. Conventional radiography (X-ray) of SIJs is the traditional method for detecting sacroiliitis and diagnosing $\mathrm{SpA}$, but it has limitations such as high interreader variability, the use of ionizing radiation, delay in diagnosis of 8-11 years, 
since it takes time to develop structural damage visible on radiographs. It is difficult to diagnose sacroiliac inflammation with conventional radiography in early and acute phases since its diagnostic capacity is limited in the period when chronic changes have not yet occurred. In contrast, MRI of SIJs can visualize both inflammatory lesions and structural damage, and MRI also more accurately reflects SIJ structural bone damage than X-ray [14].

The Assessment of SpondyloArthritis International Society included MRI into the classification criteria as an important tool for the early diagnosis of active sacroiliitis [3]. In the literature, the detection of $\mathrm{BMO} / \mathrm{O}$ in patients with sacroiliitis has been accepted as an indispensable finding of active inflammation and has been described as hyperintense signal changes on STIR and fat-saturated T2W (FS-T2W) sequence images on MRI [15].

Previous studies have emphasized that DCE-MRI improves sensitivity for the diagnosis of acute inflammatory lesions, reflecting the vascularity and perfusion characteristics of the disease, compared with the conventional sequences recommended according to the ASAS protocol $[15,16]$. In our study, there was no bone marrow oedema finding that could be detected in other sequences but not in the STIR sequence. Only 4 of the patients with bone marrow oedema in the STIR sequence did not interact with the contrast agent. Although, being BMO is the most important and common MRI feature of acute sacroiliitis, its specificity is the lowest of all features, as reported by Jans et al. So, careful assessment is fundamental to avoid falsepositive MRI reports [17]. Muche et al., reported BMO on FST2W and STIR sequences and articular contrast enhancement on postcontrast FS-T1W images were as activation criteria, but they already observed enhancement in all joints with oedema, and articular contrast enhancement was more sensitive as an indicator for activation compared to BMO, as well [18].

Therefore, there are numerous studies highlighting the importance of DCE-MRI in detecting the disease in early stages. Otveen et al., reported that early sacroiliitis could be detected on DCE - MRI while any morphological finding could not be seen on conventional radiography [19]. Also, Althoff et al., showed that DCE - MRI was useful to provide maximum diagnostic confidence in early sacroiliitis patients [20].

Other MRI features indicating active inflammation include enthesitis and synovitis/capsulitis. The latter can only be shown after contrast administration. Furthermore, advanced MR applications such as DCE-MRI and DWI, increase the sensitivity of MRI in the evaluation of disease activation [21,22].

In a study published by Gaspersic et al., both DWI and DCEMRI were shown to be effective in measuring inflammatory changes during the treatment of ankylosing spondylitis [23]. In our study, results were indicated that differentiation of early acute SpA from chronic SpA could be possible by assessing the degree of contrast enhancement, TSI curves, and ADC measurements with DCE-MRI and DWI. So, our study is one of the few studies investigating the diagnostic performance of advanced MRI applications such as DWI and DCE-MRI in the detection, quantification and staging of early/acute SpA, also its correlation with laboratory findings namely ESR and CRP.

Bollow et al., reported that there was a significant difference in contrast enhancement intensity varying with the stage of the disease [24]. Congruous with this observation, we found that patients with acute $\mathrm{SpA}$ had higher $\mathrm{F}_{\text {enh }}$ values than ones with chronic SpA. Additionally, TSI curves of acute SpA patients were predominantly as Type 2 and Type 3 .

In our study, similar to previous studies, as in the study of Şahin et al., we found that BAO was in larger areas in patients with chronic SpA than in patients with acute SpA [25]. We think this finding may help to stage the activity of the disease, together with the features of contrast enhancement and $\mathrm{ADC}$ values.

Diffusion-weighted imaging becomes a good option with rapid sequences for evaluating SIJs. ADC is a quantitative parameter calculated from diffusion-weighted images. It combines the effects of water diffusion and capillary perfusion in the extracellular-extravascular space, allowing quantification of inflammatory lesions. A local increase in water movement due to $\mathrm{BMO}$ results in increased diffusion, and measurement of high ADC values [9]. Bozgeyik et al., found higher ADC values in patients with axial SpA compared to the patients with mechanical lower back pain in the effected sacral and iliac regions [26]. Consistent with the literature, we measured higher $\mathrm{ADC}$ values from the areas of BMO.

Diffusion-weighted imaging is a sensitive method that can be used in the early diagnosis and follow-up of acute inflammatory lesions of the SIJs. The ADC values of patients with active sacroiliitis were measured to be significantly higher than those with chronic sacroiliitis in our study. Our results were similar to the results reported in Şahin et al's study [25]. The specificity and sensitivity were very high when the threshold value for ADC was set as $0.831 \times 10^{-3 \mathrm{~mm} 2 / \mathrm{s}}$.

The specificity of MRI in the detection of acute SpA was declared as $83-100 \%$ for conventional sequences, and $100 \%$ for contrast enhanced sequences in the literaature [27]. In our study, we found that the specificity values of DCE-MRI alone, DWI alone and both of their values calculated together were $87.1 \%, 83.9 \%$ and $90.3 \%$, respectively. We detected only one patient with DCE-MRI, which we could not detect with DWI. So, there is a trade-off of sensitivity and specificity of different MRI features for the diagnosis of sacroiliitis in SpA, not a single feature is sufficient [17].

C-reactive protein and ESR are the laboratory parameters of inflammation. Gezmiş et al., reported that the increase in these acute-phase reactants can be used as a marker of disease activity. Furthermore, they showed a correlation between CRP values and ADC, but there was no relationship with the ESR values [27]. In another study, Puhakka et al., found that CRP values of patients with active sacroiliitis were higher in proportion to the inflammatory activity level of the disease when compared with CRP values of active SpA patients [28]. In our study, CRP values in patients with acute $\mathrm{SpA}$ were higher than those with chronic $\mathrm{SpA}$, but we did not detect a correlation between CRP values and ADC. 


\section{Study limitations}

This study has some limitations; such as relatively few patients, especially in the acute SpA group, being a single-center study, and not performing laboratory tests on the day of MRI.

\section{Conclusion}

Maagnetic resonance imaging is the leading modality for the diagnosis and classification of $\mathrm{SpA}$ as it showes both the active and structural aspects of sacroiliitis. It is a crucial imaging technique that was included into the classification criteria as an important tool for early diagnosis of active sacroiliitis by ASAS. DCE-MRI and DWI are advanced MR techniques that enable quantitative measurement of acute inflammation that have great importance in the diagnosis of early-stage SpA. Their combined use is superior to one alone in the diagnosis of early sacroiliitis, thus, it provides a chance for early treatment to avoid morbidity.

\section{Compliance with Ethical Standards}

Ethical Approval: The study was approved by the Haydarpasa Numune Training and Research Hospital Ethics Committee (17.03.2014, 2014/18). Informed consent was obtained from all patients prior to examination.

Financial Support: No specific funding was received.

Conflict of Interest: There are no conflicting interests.

Author Contributions: SAA : Design and conceptualization of the study, recruiting the patients, support for method, technique and service, evaluation of the data, writing of the article .

HG: Recruiting the patients and collecting study material, obtaining and analyzing the data, writing of the article.

\section{REFERENCES}

[1] Rudwaleit M, Van Der Heijde D, Landewe R, et al. The Assessment of SpondyloArthritis International Society Classification Criteria for Peripheral Spondyloarthritis and for spondyloarthritis in general. Ann Rheum Dis 2011;70:25-31. doi: / 10.1136/ard.2010.133645

[2] Mandl P, Navarro-Compán V, Terslev L, et al. EULAR Recommendations for the use of Imaging in the Diagnosis and Management of Spondyloarthritis in Clinical Practice. Ann Rheum Dis 2015;74:1327-39. doi:/10.1136/ annrheumdis-2014-206971

[3] Sieper J, Rudwaleit M, Baraliakos X, et al. The Assessment of SpondyloArthritis International Society (ASAS) handbook: a guide to assess spondyloarthritis. Ann Rheum Dis 2009;68(Suppl 2):1-44 doi: 10.1136/ard.2008.104018

[4] Imkamp M, Lima Passos V, Boonen A, et al. Uncovering the heterogeneity of disease impact in axial spondyloarthritis: bivariate trajectories of disease activity and quality of life. RMD Open 2018;14;4:e000755. doi:/10.1136/ rmdopen-2018-000755

[5] Barkham N, Keen H, Coates L, et al. A randomized controlled trial of infliximab shows clinical and MRI efficacy in patients with HLA-B27 positive very early ankylosing spondylitis. Arthritis Rheum 2007;56(Suppl.):L11. doi: 10.1002/art.24408.

[6] Hermann KG, Bollow M. Magnetic resonance imaging of sacroiliitis in patients with spondyloarthritis: correlation with anatomy and histology. Rofo 2014;186:230-7. doi:10.1055/s-0033.135.0411

[7] Jevtic V, Kos-Golja M, Rozman B, McCall I. Marginal erosive discovertebral "romanus" lesions in ankylosing spondylitis demonstrated by contrast enhanced gd-dtpa magnetic resonance 1maging. Skeletal Radiol 2000;29:27-33. doi: $10.1007 / \mathrm{s} 002.560 .050005$

[8] Ward R, Caruthers S, Yablon C, Blake M, DiMasi M, Eustace S. Analysis of diffusion changes in posttraumatic bone marrow using navigator-corrected diffusion gradients. AJR Am J Roentgenol 2000;174:731-4. doi: 10.2214/ajr.174.3.1740731

[9] Navallas M, Ares J, Beltrán B, Lisbona MP, Maymó J, Solano A. Sacroiliitis associated with axial spondyloarthropathy: new concepts and latest trends. Radiographics 2013;33:933-56. doi: 10.1148/rg.334125025

[10] Catan Rudwaleit M, Haibel H, Baraliakos X, et al. The early disease stage in axial spondylarthritis: results from the German spondyloarthritis inception cohort. Arthritis Rheum 2009 Mar;60:717-27. doi: 10.1002/art.24483. doi: 10.1002/ art. 24483

[11] Catan L, Boariu M, Amaricai E, et al. Predicting functional disability in patients with spondyloarthritis using a crpbased algorithm: a 3-year prospective study. Exp Ther Med 2021;21:89. doi:10.3892/etm.2020.9521.Epub 2020 Nov 26.

[12] Braun J, Bollow M, Eggens U, König H, Distler A, Sieper J. Use of dynamic magnetic resonance 1maging with fast 1maging in detection of early and advanced sacroiliitis in spondylarthropathy patients. Arthritis Rheumatol 1994;37:1039-45 doi: $10.1002 /$ art. 178.037.0709

[13] Braun J, Bollow M, Sieper J. Radiologic diagnosis and patology of the spondyloarthropathies. Rheum Dis Clin North Am 1998;24:697-735. doi: 10.1016/s0889-857x(05)70038-7

[14] Van den Berg R, Lenczner G, Feydy A, et al. Agreement between clinical practice and trained central reading in reading of sacroiliac joints on plain pelvic radiographs. Results from the DESIR cohort. Arthritis Rheumatol 2014; 66:240311. doi: 10.1002/art.38738

[15] Baraliakos X, Landewe R, Braun J. Magnetic resonance imaging in ankylosing spondylitis. Future Rheumatol 2006;1:423-31. doi: 10.2217/17460816.1.4.423

[16] Bredella MA, Steinbach LS, Morgan S, Ward M, Davis JC. MRI of the sacroiliac joints in patients with moderate to severe ankylosing spondylitis. AJR 2006;187:1420-6. doi: 10.2214/ AJR.05.1423

[17] Jans L, Egund N, Eshed I, Sudol-Szopińska I, Jurik AG. Sacroiliitis in axial spondyloarthritis: assessing morphology and activity. Semin Musculoskelet Radiol 2018;22:180-8. doi:10.1055/s-0038.163.9470

[18] Muche B, Bollow M, Francois RJ, Seiper J, Hamm B, Braun J. Anatomic structures in early - and late - stage sacroiliitis 
in spondyloarthritis. Arthritis Rheum 2003;48:1374-84. doi: 10.1002/art.10934

[19] Otveen J, Prevo R, den Boer J, van de Laar M. Early detection of sacroiliitis on magnetic resonance imaging and subsequent development of sacroiliitis on plain radiography. A prospective, longitudinal study. J Rheumatol 1999;26:1953-8.

[20] Althoff CE, Feist E, Burova E, et al. Magnetic resonance 1maging of active sacroiliitis: do we really need gadolinium? Eur J Radiol 2009;71:232-6. doi: 10.1016/j.ejrad.2009.04.034

[21] Yu W, Feng B, Dion E, Yang H, Jiang M, Genant HK. Comparison of radiography, computed tomography and magnetic resonance imaging in the detection of sacroiliitis accompanying ankylosing spondylitis. Skeletal Radiol 1998; 27:311-20. doi: $10.1007 / \mathrm{s} 002.560 .050388$

[22] Remy M, Bouillet P, Bertin P, Leblanche AF, Bonnet C, Pascaud JL. Evaluation of magnetic resonance imaging fort the detection of sacroiliitis in patients with early seronegative spondyloarthropathy. Rev Rheum Engl Ed 1996; 63: 577-83.

[23] Gaspersic N, Sersa I, Jevtic V, Tomsic M, Praprotnik S. Monitoring ankylosing spondylitis therapy by dynamic contrast-enhanced and diffusion-weighted magnetic resonance 1maging. Skeletal Radiol 2008;37:123-31. doi: $10.1007 / \mathrm{s} 00256.007 .0407-2$

[24] Bollow M, Braun J, Hamm B, et al. Early sacroiliitis in patients with spondyloarthropathy: evaluation with dynamic gadolinium-enhanced MR imaging. Radiology 1995;194:52936. doi:10.1148/radiology.194.2.7824736

[25] Sahin N, Hacibeyoglu H, Ince O, et al. Is there a role for DWI in the diagnosis of sacroiliitis based on ASAS criteria? Int J Clin Exp Med 2015;8:7544-52.

[26] Bozgeyik Z, Özgöcmen S, Kocakoc, E. Role of diffusionweighted MRI in the detection of early active sacroiliitis. Am J Roentgenol 2008;191:980-6. doi:10.2214/AJR.07.3865

[27] Gezmis E, Donmez FY, Agildere M. Diagnosis of early sacroiliitis in seronegative spondyloarthropathies by DWI and correlation of clinical and laboratory findings with ADC values. Eur J Radiol 2013;82:2316-21. doi: 10.1016/j. ejrad.2013.08.032

[28] Puhakka KB, Jurik AG, Schiottz-Christensen B, et al. Magnetic resonance 1maging of sacroiliitis in early seronegative spondylarthropathy. abnormalities correlated to clinical and laboratory findings. Rheumatology (Oxford) 2004;43:234-7. doi: 10.1093/rheumatology/keh008 